\title{
The Strategic Planning Process and PERFormanCE RELATIONSHIP: DOES CULTURE MATTER?
}

\author{
Richard C. Hoffman \\ Salisbury University \\ Salisbury, MD
}

\begin{abstract}
Given the growth of multinationals, it is important that managers learn whether strategic planning enhances firm performance in cross-cultural situations. Using an international sample of firms, this study found that the general planning-performance model is relevant across the cultures sampled. While there appears to be little direct relationship between culture and planning, culture did moderate the planning-performance relationship. Furthermore, specific cultural values were found to account for some of the cross-cultural differences in the planning-performance relationship. Implications for management and future research are discussed.
\end{abstract}

\section{Introduction}

Concerns of increased international competition abound not only in the U.S. but also in Europe with the further expansion of the European Union and in Asia and Latin America with increased economic integration (Rugman, 2003) in those regions. Theorists (Goll \& Rasheed, 1997; Brews \& Hunt, 1999) have argued that firms should respond to environmental changes, such as increased competition, by engaging in more systematic strategic planning to anticipate and respond to changing events. There is evidence that U.S. firms have responded to greater environmental uncertainty and complexity with more extensive planning (Javidan, 1984; Kukalis, 1989). Furthermore, it appears that formal strategic planning enhances firm performance although the relationship is not unequivocal (Boyd, 1991; Capon, Farley \& Hulbert, 1994; Miller \& Cardinal, 1994). It is worth noting that, as firms in other regions of the world are confronting increasingly volatile environments, there is a need to extend planning research to firms representing a diversity of national and cultural settings (Brock, Barry \& Thomas, 2000). Such research will help ensure that current prescriptions concerning the use of planning have external validity in a variety of locales. Thus, the purpose of this study is to examine the relationship between strategic planning and firm performance among a group of firms representing different cultural regions. 


\section{Strategic Planning Processes}

Strategic management seeks to align the firm's activities with its external environment. At the heart of this management approach is the strategic planning system. As firms face increased environmental change (e.g., more globalization) theorists (Grant, 2003) argue that firms benefit from strategic planning. For over thirty years, a plethora of studies have examined formal long range or strategic planning. Many of these studies have found that firms that plan possess different characteristics than non-planners. In particular, many studies have sought to examine the relationship between planning and firm performance (Boyd, 1991). A review of much of the literature suggests that strategic planning can be described along two broad dimensions, planning content or ends and planning processes or means (Boyd, 1991; Brews \& Hunt, 1999; Miller \& Cardinal, 1994; Ramanujan \& Venkatraman, 1987). Planning content refers to the ends of the planning process such as: goals, mission statements, environmental information programs (Veliyath \& Shortell, 1993), and internal resources. Much of this content helps distinguish strategic planning from that which is purely operational planning. Planning processes focus on the means or methods by which the planning process is carried out. Characteristics such as commitment, system maturity, comprehensiveness, time horizon, and importance are typical examples of such system or process characteristics (Capon, Farley \& Hulbert, 1994; Ramanujam \& Venkatraman, 1987; Rhyne, 1986).

This study focuses on planning processes or system characteristics because these processes have been examined far more in the literature (Boyd, 1991; Miller \& Cardinal, 1994) on planning and performance. This makes it easier to compare this study to the stream of literature that has preceded it. Second, culture is believed to affect planning processes (Haiss, 1990). As Brock et al. (2000) note, cultural values shape acceptable organization processes such as planning and decision making. Furthermore, Hofstede (2001) has observed that planning processes often reflect the dominant values of a culture.

Previous studies have examined the planning and performance relationship in non-U.S. settings, but the results have been mixed. There was no consistent relationship between formality of planning and firm performance among Swedish firms (Rhenman, 1973), Canadian firms (Sheehan, 1975), or British firms (Grinyer \& Norburn, 1975). However, positive relationships between formal planning and performance have been observed between planning importance/impact and performance among Australian firms (Burt, 1978), Finnish firms (Harju, 1981), and another sample of British firms (Smith, 1980). Thus, planning processes other than formality do appear to be related to performance in these latter studies. Similarly, U.S. planning and performance studies suggest significant correlations between strategic planning processes and relevant measures of firm performance (Boyd, 1991; Miller \& Cardinal, 1994; Shrader, Taylor \& Dalton, 1984) when the planning processes other than the formality of the system are examined (Brews \& Hunt, 1999). Since strategic planning helps the firm focus its attention on salient 
environmental trends and define the firm's goals, the act of going through such a process should enhance the firm's performance. In the case of multinationals facing multiple changing environments (Brock \& Barry, 2003; Goll \& Rasheed, 1997; Grant, 2003; Miller \& Cardinal, 1994), planning should have a positive effect on firm performance. Taken as a whole these studies suggest that strategic planning may be related to performance for most multinationals in today's changing global markets.

Hypothesis 1: Strategic planning processes will be positively related to performance among multinational firms representing a variety of social cultures.

\section{Culture and Planning}

Previous research (Brews \& Hunt, 1999; Goll \& Rasheed, 1997; Miller \& Cardinal, 1994) has indicated that the firm's context may mitigate the planningperformance relationship, such factors as company size, industry, environmental change, and firm strategy. In a cross-national setting another contingency likely to affect this relationship is social culture. Culture is defined as the values, attitudes and behaviors shared by the peoples of a region (Hofstede, 2001). A culture represents assumptions, values, and behaviors that have enabled people to successfully adapt to their external environment. Since strategy is the means by which firms seek to adapt to their environments, a link between culture and strategy appears likely (Schneider \& Barsoux, 2003). Culture may influence the strategic planning process (Brock et al., 2000) and, thereby, firm performance in the following ways. First, culture shapes the way people think, behave, and evaluate (Hofstede, 2001; Schneider \& Barsoux, 2003). This, in turn, affects decision processes such as planning. Second, cultures vary along critical values and beliefs that affect a variety of management processes including planning.

The concept of culture is broad, making assessment difficult (Leung, Bhagat, Buchan, Erez \& Gibson, 2005). There are essentially two means of assessing culture: culture-centered and personality-centered approaches (Clark, 1990; Lenartowicz \& Roth, 1999). Culture-centered approaches use qualitative anthropological approaches to describe a single culture in terms of its ethnology, religion, customs, etc. This approach is suitable when studying a single culture. Personality-centered assessments use quantitative measures. Some of these can be proxies such as nationality or place of birth. Another personality-centered method is the use of value inferences based on either primary or secondary measures. This study uses two personality-centered assessments because they provide quantitative secondary measures, capture different aspects of culture, and enable us to compare across multiple cultures.

The primary assessment of culture used in this study is based on Ronen and Shenkar's (1985) cultural clusters. These were empirically derived from eight major studies of goals, values and norms in work settings. This measure reflects 
that cultures extend beyond national boundaries by grouping nations based on similarity of goals, values, and norms. Our secondary assessment is an indirect values inference measure based on Hofstede's (2001) value dimensions of power distance (degree of status differences), uncertainty avoidance (fear of unknown and risk taking), assertiveness (emphasis on results versus process), and self-orientation (individual versus collective self-identity). This assessment of culture has been widely used in management research (Leung et al, 2005; Sivakumar \& Nakata, 200l) but to a much lesser extent in planning research (Haiss, 1990). Brock et al. (2000, p. 689) have described these value dimensions, "... as perhaps the most straight forward means to describe systematic cultural variation ..." and, therefore, particularly applicable for examining planning in the multinational firm.

The use of these two assessments of culture makes it easier to relate this study to previous research (Haiss, 1990; Hoffman \& Hegarty, 1993). Employing cultural clusters is a coarser measure in that nations are grouped into a cluster based on a variety of information regarding prevailing work goals and values. It is coarser because it is essentially a nominal measure. This is our primary cultural assessment because this study is exploratory and not much is known about how specific cultural characteristics impact planning. Our second assessment of culture is based on Hofstede's (2001) values data for the nations in our sample. This measure permits us to examine an exploratory hypothesis regarding the potential effects of specific cultural values on the planning-performance relationship.

Given that firms from the triad nations (North America, Europe, and Japan) lead the world in international business activities (Rugman, 2003), cultures from Western Europe and North America were selected as the focus of this study because they represent two of the three prongs of the triad. In addition, specific nations were selected to provide cultural diversity and because of their accessibility for data collection. Based on Ronen and Shenkar's (1985) typology, the following cultural groups are represented in the study: Anglo (the U.K., USA), Germanic (Germany, Switzerland), and Nordic (Denmark, Finland, Netherlands, Norway, and Sweden). This study emphasizes cultural rather than national differences because culture transcends national boundaries and appears to cause more variations in managerial attitudes and activities (Hofstede, 2001).

Cultures that perceive a greater control over their environments and that can tolerate ambiguity tend to use a more rational/analytic, top down approach to strategy making (Schneider \& Barsoux, 2003). Individuals operating in cultures with the opposite value profile perceive they have less control over their environment so strategy making follows a less methodical approach. Compared to the higher uncertainty avoidance Germanic culture, "Managers from Nordic and Anglo countries are less likely to see environments as uncertain," and more likely to believe environments can be analyzed and known through rational processes such as strategic planning (Schneider \& Barsoux, 2003, p. 122). Since the Anglo and Nordic cultures are similar on the beliefs most associated with rational strategic planning processes, we expect the following: 
Hypothesis 2: Managers from Anglo and Nordic cultures will place a stronger emphasis on various strategic planning processes than those from Germanic cultures.

\section{Planning, Performance and Culture}

Culture has been found to moderate strategic decision processes (Hoffman \& Hegarty, 1993) and perceptions of strategic strengths and weaknesses (Schneider \& De Meyer, 1991). While strategic planning and performance has been examined in non-U.S. locales, only a few of these studies have examined strategic planning in a cross-national setting. Horovitz (1980) found that German and British firms engaged in long-range planning more than French firms. Haiss (1990) found that certain planning process characteristics (e.g., planning horizon, use of quantitative methods, types of plans, etc.) and planning content (e.g., objectives, forecasts) varied among banks within ten different nations; he speculated that cultural differences were the reasons behind his observations. Recently, a study among smaller firms found that the relationship between detailed planning and non-financial firm success was moderated by culture (Rauch, Frese \& Sonnentag, 2000 ). These studies suggest that the strategic planning process and the planning performance relationship do differ among cultures.

Insights regarding why or how planning and performance differs across cultures investigated here are provided by a few studies. Since strategy enables the firm to adapt to its environment, how managers perceive and react to environmental uncertainty is relevant to strategy making. Previously, we noted that Anglo and Nordic cultures believe the environment can be analyzed and known (Schneider \& Barsoux, 2003). As a result, managers from these cultures are attracted to analytical approaches to strategic planning. Case studies of Nordic firms from Denmark (Schneider \& Barsoux, 2003) and Sweden as well as U.S. (Anglo) firms (Schneider, 1989) have noted the use rational/analytic approaches to strategic planning. Differences in strategic planning processes between Anglo (e.g., U.K. and U.S.) and Germanic (e.g., German) firms have been observed in two other studies. Horovitz (1980) found that British firms, compared with German firms, used planning that was more strategically versus operationally oriented, used a longer time horizon, and placed more emphasis on performance. Haiss (1990) found that, compared to U.S. firms, German firms used a longer planning horizon, planned on a less regular basis, and conducted planning more as a staff versus a line function. The overall planning process among the U.S. firms was rational and analytical; whereas, the Germans employed a more political process.

Taken together, these studies suggest that the strategic planning processes of Anglo and Nordic firms appear to be similar to each other while the processes within German firms appear to differ from the rational/analytical planning model. The planning process characteristics examined in this study are typical of the rational/analytical approaches to strategic planning. Moreover, most of the studies 
relating planning to firm performance have described rational/analytic approaches to strategic planning. Thus, the following hypothesis is offered:

Hypothesis 3: Culture will moderate the relationship between strategic planning and firm performance:

Hypothesis 3a: Strategic planning processes will be positively related to performance within the Anglo and Nordic cultures, and

Hypothesis 3b: Strategic planning processes will exhibit a weaker relationship to firm performance within the Germanic culture.

In this section we briefly explore some possible relationships that Hofstede's (2001) value dimensions might have with planning and its subsequent impact on firm performance. Schneider and Barsoux (2003) have argued that uncertainty avoidance affects the overall planning process; whereas, power distance is likely to affect the degree to which the planning process is structured (Hofstede, 2001). Self-orientation seems to affect the managerial relationships among those engaged in the planning process (Schneider \& Barsoux, 2003). High power distance cultures are expected to have a top-down highly structured planning approach (Brock et al., 2000). Uncertainty avoidance may be associated with: increased planning activity (Hofstede, 2001), the perceived importance of planning, and the length of planning time horizon (Haiss, 1990). For example, low uncertainty avoidance cultures tend to favor more flexible, short-term strategic planning processes (Brock et al., 2000).

Individualist values affect planning relationships as well as the comprehensiveness of the planning system (Schneider \& Barsoux, 2003). Individualistic cultures allow for more variety/flexibility in the planning process; whereas, collective cultures pursue cooperation and expect all to conform to the same process (Brock et al., 2000). In competitive, masculine cultures tight, structured planning processes are preferred to insure desired results (Steensma, Marino \& Weaver, 2000). Feminine cultures prefer planning processes that are flexible and bottom-up (Brock et al., 2000).

The above discussion suggests that these cultural values appear to be associated with differing characteristics of the planning process. Thus, we propose the following exploratory hypothesis:

Hypothesis 4: Formal strategic planning processes will be positively related to firm performance given the following cultural values:

Hypothesis 4a: higher levels of power distance

Hypothesis $4 \mathrm{~b}$ : lower levels of uncertainty avoidance.

Hypothesis $4 \mathrm{c}$ : higher levels of individualism, and/or

Hypothesis $4 \mathrm{~d}$ : lower levels of masculinity.

As noted previously, different contingencies, in addition to the firm's culture, are likely to affect the planning-performance relationship. Thus, the tests of the 
hypotheses will control for three primary contingencies as identified in previous research. These contingencies include industry and company size which were identified as variables affecting firm performance in meta-analyses (Boyd, 1991; Miller \& Cardinal, 1994) of the planning and performance relationship. Firm strategy has emerged more recently as an important contingency variable (Schneider \& Barsoux, 2003; Veliyath \& Shortell, 1993) when examining the strategic planning and performance relationship. As one study recently noted, "Strategy moderates the relationship between planning and firm performance," (Rogers, Miller \& Judge, 1999, p. 574). Following this latter study, strategy is represented by Miles and Snow's (1978) typology because it has been found to be valid in a variety of firms and industries (James \& Hatten, 1995; Shortell \& Zajac, 1990; Zahra \& Pearce, 1990). The typology classifies firms as pursuing one of the following four strategies: defender (narrow focus and efficiency), prospector (innovativeness), analyzer (operating in multiple environments), or reactor (no consistent strategy).

\section{Research Methods}

\section{Sample and Data}

The data for this study were collected by using a mailed questionnaire sent to a stratified (by country and size) random sample of 150 manufacturing firms selected from national directories of major multinationals. Firms had to be of sufficient size to increase the likelihood of their familiarity with formal strategic planning and to insure ample publicly available data on firm and performance characteristics. Questionnaires were mailed to the corporate planner or senior executive in each firm most familiar with the firm's strategic planning processes as designated by the CEO. Prior to translations, the questions were pre-tested with managers from each of the three cultural groupings for congruence in understanding. Minor changes were made to insure the meaning was consistent across cultures. The questionnaires were available in English and German. Translations were verified and pre-tested using the multi-step, back-translation procedure developed by Hoffman and Hegarty (1983). Data on firm size, industry, age, and objective firm performance were obtained from secondary sources - directories providing business and financial information.

An international sample of 75 firms provided data (18 firms chose not to participate for a variety of reasons; 2 provided incomplete data), yielding a $57.7 \%$ net response rate; this sample size compares favorably with similar studies of this type (Rauch et al., 2000; Ramanujam \& Venkatraman, 1987). Ninety-one percent of the responding managers were born and educated in the country/culture in which their firm was located. One of the non-natives received most of his education in his current country of work. Furthermore, $94 \%$ of the top management teams of the firms were native to the culture of their firm's location. This provides some confidence that perspectives of each culture are represented in our respondents. Additional statistical tests were conducted to further insure that 
our cross-cultural results are not confounded by other factors. A comparison of the responding firms with non-respondents revealed no systematic differences in terms of size, industry or nationality. The firms are located in eight European countries (Denmark, Finland, Germany, Netherlands, Norway, Sweden, Switzerland, and U.K.) and the United States. On average the sample firms produce durable goods, generate $\$ 6.1$ billion in sales, employ about eighteen thousand people, have been in existence for almost a century, and tend to pursue more proactive analyzer and prospector strategies. Nevertheless, the proportion of firms pursuing each strategy falls well within the ranges observed in other studies (Rogers et al., 1999; Zahra \& Pearce, 1990). Table 1 also breaks down the firm characteristics by cultural grouping.

\section{Variable Measurement}

Strategic Planning Processes were assessed using several variables/dimensions and were all subjective measures. We selected planning scales used by studies cited in the meta-analyses of past planning and performance studies (Boyd, 1991; Miller \& Cardinal, 1994). The use of previous scales provides measures with criterion-related validity and permits comparisons with previous studies. Planning maturity was assessed using Rhyne's (1986) single item scale $(1=$ new system, 3 = basic system with annual changes, $5=$ mature system). Planning impact was assessed using two items (alpha $=.90)$ one drawn from Rhyne (1986) concerning the value of long range planning and an effectiveness item relating to the usefulness of the system (Ramanujam \& Venkatraman, 1987). Planning horizon was adapted from one item $(1=$ less than a year to $5=10+$ years) drawn from Rhyne (1986). Planning importance was assessed by a 4 item (alpha $=.80)$ scale $(1=$ not important to $5=$ extremely important) also taken from Rhyne (1986). Finally, planning commitment was a planning process variable developed for this study at the suggestion of managers used in the pretests to capture the firm's commitment to the planning process now and in the future. The commitment scale is comprised of two items pertaining to the use of formal strategic planning now and in the future $(1=$ not important to $5=$ extremely important). These items were factor analyzed and comprised a single factor so they were averaged to provide a single measure for planning commitment, exhibiting good reliability, alpha $=88$.

Culture was assessed by two methods as discussed earlier. The first method was the use of country clusters based on the work of Ronen and Shenkar (1985). The nine nations were classified into three cultural groups (nations, number of firms): Anglo (United Kingdom - 7, United States - 23), Germanic (Germany -11 , Switzerland -10 ) and Nordic (Denmark - 1, Finland -4, Netherlands -9, Norway -2 , Sweden -8 ). Culture was operationalized as two dummy variables Germanic and Nordic, a zero on both of these variables represents the Anglo culture in the analyses. The second method was the use of Hofstede's (2001) value indices for four social values of power distance, uncertainty avoidance, individualism, and masculinity. These indices range from $0-115$ and were drawn 
from Hofstede's data for each country in our sample. The two measures of culture capture different aspects of the concept as revealed by the low average intercorrelation among the two methods used of $r=-.22$.

\section{Table 1}

Firm Characteristics: Means and Percentages

$$
(\mathrm{N}=75)
$$

\section{Total Sample}

Sales: $\$ 6.1$ bln. $(\$ 30 \mathrm{mil}-76.4 \mathrm{bln})^{1}$

Country (no. of firms) $)^{2}$ :

Denmark (1) ${ }^{\mathrm{N}} \quad$ Sweden $(8)^{\mathrm{N}}$

Finland (4) ${ }^{\mathrm{N}} \quad$ Switzerland $(10)^{\mathrm{G}}$

Germany (11) ${ }^{;}$United Kingdom (7) ${ }^{\wedge}$

Netherlands (9) ${ }^{N}$ USA (23)^

Norway (2) ${ }^{\mathrm{N}}$
Employees: 17,583 (375 - 368 K)

Firm age: 98.7 yrs $(21-248)$

Strategy ${ }^{3}$ :

Defenders (7) $\quad 9.69 \%$

Analyzers (35) $\quad 46.7 \%$

Prospectors (25) $33.3 \%$

Reactors (6) $\quad 8.2 \%$

Industry:

Durable Goods: $\quad$ (42) $56 \%$

Non-durables: $\quad$ (33) $44 \%$

\section{Culture:}

No. Firms

Sales

Countries

Employees

Firm age (yrs)

Industry:

Durables

Non-durable

Strategy: ${ }^{3}$

Defenders

Prospectors

Analyzers

Reactors
(19) $63 \%$

(11) $37 \%$

(3) $10 \%$

(9) $30 \%$

(16) $53 \%$

(1) $3 \%$

\section{Germanic}

21

$\$ 7.4$ bln.

2

$29.5 \mathrm{k}$

103.2
Nordic

24

$\$ 9.9$ bln

5

$14.8 \mathrm{k}$

98.4

$\begin{array}{lll}95.4 & 103.2 & 98.4\end{array}$

' $\mathrm{k}=$ thousands; mil $=$ millions; bln $=$ billions.

2 Cultural group: $\mathrm{A}=$ Anglo culture; $\mathrm{G}=$ Germanic culture; $\mathrm{N}=$ Nordic culture.

3 Two firms did not provide data. 
Furthermore, as a validity check for our first measure based on cultural groupings, Hofstede's (2001) value data for each country were averaged by country cluster and means were compared using ANOVA's. There were significant differences for all four values across the three cultural groups $(F=25.6$ to 1142.4, all at $p<.0001$ ) indicating that the three cultural groups are significantly different on these values (see Appendix). Moreover, these results reveal that Hofstede's (2001) values do help discriminate among the cultural groups in our sample.

Firm financial performance was assessed in two ways using subjective as well as objective measures. Subjective measures were chosen given the difficulty of obtaining complete objective financial data in a multinational sample of firms. The four-item scale developed by Dess and Robinson (1984) has the respondents assess a firm's return on assets (ROA), return on sales (ROS), 5-year sales growth, and overall performance relative to similar firms in its industry and region $(1=$ lowest $20 \%$ to $5=$ top $20 \%$ ). The subjective measures of ROS, ROA, and sales growth were significantly correlated with objective measures of these same performance measures among a sub-sample of firms for the year preceding the data collection (mean $r=.30$ range .22 to $.42, p \leq .03$ ). This correlation with current performance is consistent with the findings of Dess and Robinson, (1984). The four subjective measures loaded on a single factor (Eigenvalue $=2.81$, variance accounted for $70.1 \%$, alpha $=.88$ ), and therefore, were averaged as a single measure of subjective firm performance.

Sufficient data were obtained for the year of data collection and three years following our survey to provide objective measures of sales growth and return on assets averaged over this same four year period. These objective measures were not significantly correlated (mean $\mathrm{r}=.06$, range -.11 to .01 ) with their subjective counterparts suggesting that they tap different aspects of future firm performance relative to the data collection period. On the other hand, the subjective performance data appears to reflect current performance (correlated with objective measures near the time of data collection). These objective measures were selected because of their prevalence in previous planning-performance studies (Boyd, 1991) and their availability in secondary sources.

Strategy was subjectively measured by the respondents using Miles and Snow's (1978) self-typing procedure; wherein, the respondent classifies their firm's strategy as either defender (narrow product line and emphasis on efficiency of operation), prospector (search for new opportunities/innovations), analyzer (operate in stable and changing markets simultaneously), or reactor (lacks a consistent strategy). This strategy measure has been found to have considerable criterion-related validity (James \& Hatten, 1995). These strategic classifications were converted to an interval-type scale as developed by Shortell and Zajac (1990) providing a measure of the firm's strategic orientation $(1=$ reactor, $3=$ defender, $5=$ analyzer, and $7=$ prospector) .

The remaining control variables of industry and size were objective measures obtained from archival sources. Since all firms were in manufacturing, they were classified as manufacturers of either durable (e.g., electronics, vehicles) or non- 
durable goods (e.g., food, chemicals), so industry was represented by a dummycoded variable. Size was measured as the average number of employees over the same four-year period as the objective performance measures.

\section{Analysis}

Prior to testing the hypothesis, additional tests were run on the data to insure that responses were not confounded by factors not already accounted for in our tests. These tests revealed that responses to planning processes were not affected by the managers' country of citizenship, education level, nor years working for their firm (Hotelling's $T$ ranged from .08-.16 at $p$ levels of .35-.65). Furthermore, the planning process did not differ based on firm performance $(\mathrm{p} \leq .25)$ indicating that firm performance did not appear to affect the use of planning processes. Thus, it does appear that higher performance does not necessarily lead to differential planning processes.

The first hypothesis concerning the stability of the planning-performance relationship across cultures was assessed with regression analysis. Subjective performance was regressed on planning characteristics while controlling for culture, industry, firm size and strategy. The second hypothesis regarding the differences in planning process characteristics was assessed using multiple analysis of covariance (MANCOVA) with the five planning process variables as the dependent variables, culture as the independent factor, and the control variables (i.e., firm size, industry, and strategy) as the covariates. The third hypothesis concerning variations in planning-performance across cultures was assessed by dividing the sample into three cultural sub-samples. Within each cultural grouping, partial correlation coefficients were calculated between each planning process variable and both subjective and objective (i.e., sales growth and ROA) measures of firm performance while controlling for industry, firm size, and strategy. Support for this hypothesis is established when one or more of the planning process variables is significantly related to one or more of the measures of firm performance. Significant partial correlation coefficients were compared across cultures using Fisher's $Z$ test for correlation coefficients. The fourth hypothesis concerning the moderating effects of cultural values on the planning-performance relationship was assessed with a series of five moderated regression analyses, one for each planning variable. The control variables (size, industry, strategy), cultural values, and a planning variable were entered first into each equation followed by four interaction terms of each cultural value (score standardized to minimize multicollinearity) multiplied by the planning variable in the equation. It can be expressed as follows:

$$
\begin{aligned}
Y_{\text {perf }}= & \left(C_{\text {size }}+C_{\text {ind }}+C_{\text {strat }}\right)+\left(V_{\text {pd }}+V_{\text {ua }}+V_{\text {idv }}+V_{\text {mas }}\right)+P_{\text {lanx }}+ \\
& \left(P_{x}^{*} V_{\text {pd }}+P_{x}^{*} V_{\text {ua }}+P_{x}^{*} V_{\text {idv }}+{ }_{x} P^{*} V_{\text {mas }}\right)
\end{aligned}
$$

where $\mathrm{C}=$ control variables, $\mathrm{V}=4$ values (pd, ua, idv, mas), $\mathrm{P}_{\mathrm{x}}=$ one of five planning processes, and $\mathrm{P}_{\mathrm{x}} * \mathrm{~V}_{\mathrm{x}=}$ the interaction term between each value and the planning process investigated. 
For each moderated regression equation, the dependent variable was subjective firm performance ( $\mathrm{Y}_{\text {perf }}$ ) given the need for adequate sample size. Objective performance measures had too many missing values for these analyses. Significant interaction terms $\left(\mathrm{P}_{\mathrm{x}} * \mathrm{~V}_{\mathrm{x}}\right)$ would indicate a moderating effect for the associated cultural value.

\section{Results}

The first hypothesis concerning the positive relationship between strategic planning and firm performance does appear to be relevant across all three cultures, supporting the hypothesis. Subjective (S) performance was regressed on the planning process variables controlling for culture, industry, size, and strategy. The results are displayed in Table 2 . The overall equation is significant $(\mathrm{F}=2.18$, df $10,64, p \leq .03$ ). Two of the five planning process variables, planning system maturity and planning impact, were significantly and positively associated with firm performance. These relationships hold up across all three cultural groups, therefore, partially supporting the hypothesis for subjective firm performance. Two of the control variables were significantly associated with performance -- firm size and strategy. Neither culture nor industry had a direct effect on firm performance. The results were the same for both cultural measures so only those for the cultural grouping measure are displayed in the table. Similar tests were not conducted for objective performance measures due to insufficient data and sample sizes.

Table 2

Performance Regressed on Planning Processes Across Cultures $(\mathrm{N}=75)$

\begin{tabular}{lll}
\hline & Variables & Beta \\
\hline Controls: & Industry & .08 \\
& German & .09 \\
& Nordic & .10 \\
& Size & $.22+$ \\
Planning: & Strategy & $.30^{* *}$ \\
& Maturity & $.21+$ \\
& Impact & $.31^{*}$ \\
& Horizon & -.12 \\
& Importance & -.14 \\
& Use & -.04 \\
\hline
\end{tabular}

$F=2.18^{*}(\mathrm{df} 10,64)$

$$
\begin{array}{rl}
* * & \mathrm{p} .<.01 \\
* & \mathrm{p}<.05 \\
+ & \mathrm{p}<.10
\end{array}
$$


The second hypothesis concerning the planning emphasis of Anglo and Nordic cultures was marginally supported. The results of MANCOVA (see Table 3 ) were marginally significant (Hotelling's $\mathrm{T}=0.31, \mathrm{~F}=1.86, \mathrm{P} \leq .06$ ). One way ANCOVAs revealed cultural differences only for the planning horizon dimension $(\mathrm{F}=7.48, \mathrm{P} \leq .001)$. Post hoc tests $(\mathrm{LSD})$ revealed that Germanic firms used a longer planning horizon (mean $=4.70)$ than firms from either Anglo $($ mean $=3.54)$ or Nordic (mean $=3.50$ ) cultures contrary to the hypotheses. There is no significant difference among the cultural groups for any of the other four planning system characteristics, contrary to the hypothesis.

Table 3

Mean Differences in Planning Processes Across Cultures

MANCOVA Hotellings $\mathrm{T}=\mathbf{0 . 3 1}, \mathrm{F}=\mathbf{1 . 8 6}, \mathrm{P} \leq \mathbf{. 0 6}$.

\begin{tabular}{llll}
\hline ANOVA Results: & $\begin{array}{c}\text { Anglo } \\
(\mathbf{N}=\mathbf{3 0})\end{array}$ & $\begin{array}{c}\text { Germanic } \\
(\mathbf{N}=\mathbf{2 1})\end{array}$ & $\begin{array}{c}\text { Nordic } \\
(\mathbf{N}=\mathbf{2 4})\end{array}$ \\
\hline Planning: & & & \\
Maturity & 3.36 & 3.40 & 3.23 \\
Impact & 3.68 & 3.83 & 3.52 \\
Horizon* & 3.54 & 4.70 & 3.50 \\
Importance & 1.97 & 2.30 & 2.14 \\
Commitment & 3.88 & 3.85 & 3.67 \\
\hline
\end{tabular}

a covariates were industry, size, and strategy

$+\quad \mathrm{p} \leq .10$

* $\mathrm{p} \leq .05$

The third hypothesis concerning stronger planning-performance relationships among the Anglo and Nordic cultures was partially supported, and the results are presented in Table 4. Partial correlation analysis within cultural groups, controlling for industry, firm size, and strategy, reveal more significant positive correlations between planning process variables and firm performance within the Anglo $(4 / 15$ correlations or $27 \%)$ and Nordic (3/15 correlations or $13 \%)$ cultures as compared to the Germanic culture ( $1 / 15$ correlations or $7 \%$ ), as hypothesized (see Table 4). In total $18 \%$ of the planning-performance correlations were significant.

Planning system maturity was not significantly related to any measure of firm performance among the Anglo sample but was positively related to subjective performance (SP) within both the Germanic and Nordic samples. However, in both 
of these cultures, system maturity was also negatively related to sales growth. The difference between the two positive correlations was significant $(z=5.16$, $\mathrm{p} \leq .001$ ) indicating that system maturity was more strongly related to performance among the Germanic firms, contrary to the hypothesis. The significant negative correlations were not significantly different from each other. Overall, the results for system maturity do not support the hypothesis. Planning system impact was significantly and positively related to the three measures of performance within the Anglo culture and negatively related to sales growth within the Nordic culture. Planning impact was not significantly related to firm performance within the Germanic sample, providing some support for the hypothesis. Planning horizon was not significantly related to any performance measure within the Anglo and Germanic samples but was positively related to ROA within the Nordic culture providing partial support for the hypothesis regarding the Nordic sample. The hypothesis regarding planning importance was not supported. There was only one significant relationship to subjective performance within the Nordic culture, but it was negative, contrary to the hypothesis. Finally, planning commitment was positively related to at least one performance measure within the Anglo (sales growth) and the Nordic (ROA) samples but not within the Germanic sample. These results support the stronger relationship between planning and performance within the Anglo and Nordic cultures, as hypothesized.

Table 4

Partial Correlations of Planning and Performance by Culture Controlling for Industry, Size, and Strategy

\begin{tabular}{|c|c|c|c|c|c|c|c|c|c|}
\hline \multirow{3}{*}{$\begin{array}{l}\text { Culture: } \\
\text { Planning/P } \\
\text { Maturity }\end{array}$} & \multicolumn{3}{|c|}{ Anglo } & \multicolumn{3}{|c|}{ Germanic } & \multicolumn{3}{|c|}{ Nordic } \\
\hline & SP' & $\begin{array}{l}\text { ce: } \\
\text { Sales } \\
\text { Growth }\end{array}$ & ROA & $S P^{1}$ & $\begin{array}{c}\text { Sales } \\
\text { Growtl }\end{array}$ & ROA & $S P^{1}$ & $\begin{array}{l}\text { Sales } \\
\text { Growth }\end{array}$ & ROA \\
\hline & -.09 & .03 & -.19 & $.39+$ & $-.44+$ & -.26 & $.30+$ & $-.40+$ & .31 \\
\hline Impact & $.47^{*}$ & $.48^{*}$ & $.48^{*}$ & -.19 & .32 & .22 & .11 & $-.57 * *$ & .14 \\
\hline Horizon & .15 & -.17 & -.16 & -.04 & .33 & -.23 & $-.44^{*}$ & $-.52^{*}$ & $.44+$ \\
\hline Importance & .21 & .07 & .10 & -.28 & .01 & -.24 & $-.60^{* *}$ & * $=.18$ & -.24 \\
\hline Use & -.13 & $.36+$ & -.13 & -.06 & .17 & .39 & .02 & .09 & $.41+$ \\
\hline
\end{tabular}

1 $\mathrm{SP}=$ subjective performance

** $\quad \mathrm{p}<.01$

* $p<.05$

$+p<.10$ 
In those instances where a given planning process variable was significantly related to the same performance measure, the differences were not always significant. For example, system maturity was negatively and significantly related to sales growth within the Germanic and Nordic cultures, but the differences in the correlation coefficients between the two samples were not significant $(z=-.096$, $\mathrm{p} \leq$ 93). However, planning impact was positively and significantly related to sales growth among Anglo firms but negatively related to sales growth among Nordic firms, the difference in correlations was significant $(z=2.52, p \leq .02)$.

Forty-three percent ( 6 of 14 ) of the significant correlations were negative and most of these negative planning-performance relationships were within the Nordic sample. These results reveal the lack of a simple relationship between planning and different performance measures across cultures.

There was some support for Hypothesis 4 concerning the moderating effects of cultural values on the planning-performance relationship. The moderated regressions for three of the five planning processes on subjective firm performance were significant, see Table 5 . The moderated regressions for planning maturity and planning horizon were not significant once the interaction terms were entered into the equation, indicating no cross-cultural difference in the planning performance relationship for these processes contrary to Hypothesis 4 . The moderated regressions for each of the other planning processes were significant after the interactions between planning and cultural values were entered into the equations, in support of the hypothesis. For planning impact the interaction terms with power distance were significant and positive (partial corr. or $\mathrm{pr}=.24$ ) while that for uncertainty avoidance was highly significant and negative $(\mathrm{pr}=-.32)$. These results indicate that planning impact is more strongly related to firm performance in cultures having higher levels of power distance and lower levels of uncertainty avoidance, supporting Hypotheses $4 \mathrm{a}$ and $4 \mathrm{~b}$. There were no findings in support of Hypotheses $4 \mathrm{c}$ and $4 \mathrm{~d}$ for planning impact.

The moderated regression for planning importance was also significant. The interaction between planning importance and uncertainty avoidance was highly significant and negative $(\mathrm{pr}=-.21)$ while that for masculine values was significant and positive $(\mathrm{pr}=.28)$. This suggests that planning importance is more strongly related to performance in cultures having lower levels of uncertainty avoidance supporting Hypothesis $4 \mathrm{~b}$ and higher levels of masculinity contrary to Hypothesis $4 \mathrm{~d}$. Hypotheses $4 \mathrm{a}$ and $4 \mathrm{c}$ were not supported for planning importance. Finally, the moderated regression between cultural values and planning commitment was also significant. Only the interaction term for power distance was significant and positive $(\mathrm{pr}=.22)$ indicating that planning commitment is more strongly related to firm performance in cultures having higher levels of power distance supporting Hypothesis 4a. The results for planning commitment did not support the other parts of Hypothesis 4.

Thus, some support was found for the moderating effect of three of the four cultural values on at least one of the planning processes examined. Only individualist values did not moderate the relationship between any of the planning processes 
Table 5

Moderated Regressions Examining the Effects of Cultural Values on the Planning-Performance Relationship

Dependent variable: Subjective Performance

(df Full Model 12,62)

\begin{tabular}{|c|c|c|c|c|c|}
\hline $\begin{array}{l}\text { Planning Process } \\
\text { Model: }\end{array}$ & Maturity & Impact & Horizon & Importanc & Commitment \\
\hline \multirow[t]{2}{*}{ Equation Statistic } & $\begin{array}{l}F=1.26 \\
R^{2}=.09^{a}\end{array}$ & $\begin{array}{c}F=2.46^{\star} \\
R^{2}=.19\end{array}$ & $\begin{array}{l}F=1.48 \\
R^{2}=.07\end{array}$ & $\begin{array}{c}F=2.25^{\star} \\
R^{2}=.17\end{array}$ & $\begin{array}{c}F=1.92^{*} \\
R^{2}=.13\end{array}$ \\
\hline & \multicolumn{2}{|c|}{ Interaction Term } & \multicolumn{2}{|c|}{ partial corr. (pr) } & \\
\hline $\mathrm{PD} x$ & .14 & $.24+$ & .08 & .07 & $.22+$ \\
\hline $\mathrm{UAx}$ & -.08 & $-.32 * *$ & -.11 & $-.21+$ & -.08 \\
\hline IDV $x$ & -.15 & -.19 & -.08 & .07 & -.18 \\
\hline MAS $x$ & .04 & .02 & .20 & $.28^{*}$ & -.03 \\
\hline$\therefore \quad$ adjusted $\mathrm{R}^{2}$ & & & & & \\
\hline$* * \quad \mathrm{p} \leq .01$ & & & & & \\
\hline$* \quad p \leq .05$ & & & & & \\
\hline$+p \leq .10$ & & & & & \\
\hline
\end{tabular}

and firm performance measures investigated. It does appear that differences in cultural values can partially explain the planning-performance relationship across national cultures.

\section{Summary and Conclusions}

This study helps establish the validity of a systematic planning-performance relationship among firms from different cultures. The results of this study found support for three of the four hypotheses investigated. The perceived use of planning system characteristics investigated here did not vary much across the three cultural groups examined. However, when controlling for industry, firm size, and strategy, strategic planning processes were positively and significantly associated with subjective firm performance. These results establish the validity of the planning-performance relationship among multiple cultures. In the investigation of the second hypothesis, culture had little direct or independent relationship to planning. However, the results of testing the third hypothesis reveal that the strength of the planning-performance relationship does indeed vary by culture. Moreover, it appears that culture has a moderating effect similar to that found in other studies (Hoffman \& Hegarty, 1993) of strategic decision processes. 
In this study, the planning-performance relationship appeared strongest within the Nordic culture with three of the five planning system characteristics positively related to one or more measures of firm performance. Two of the planning characteristics were positively related to performance among the Anglo culture while only one was significantly related to performance within the Germanic culture, thus, supporting the hypothesis.

The significant planning-performance relationships within the Anglo culture were all positive, similar to that found in the majority of U.S. studies (Boyd, 1991; Miller \& Cardinal, 1994). However, within the Germanic and especially the Nordic samples, the planning -performance relationship was often negative. Furthermore, a planning characteristic such as time horizon had a negative relationship with sales growth and a positive relationship with ROA in the Nordic culture. It may be that the planning horizon in Nordic cultures is more directed toward the long-term as opposed to more immediate short-term growth. More needs to the known about the relative emphasis placed on certain performance measures in different regions of the world.

The results of testing our final hypothesis indicate that specific cultural characteristics such as values may help explain what aspects of culture moderate the planning-performance relationship. Three of the four values were found to moderate the relationship between firm performance and three of the five planning processes investigated. Most of the significant interaction terms were in the predicted direction. These findings provide empirical support for prior observations (Haiss, 1990) and conceptualizations (Brock et al., 2000; Brock \& Barry, 2003) regarding cultural values and planning.

This study is subject to a number of limitations. The sample size is somewhat small reflecting the cost and difficulties of cross-cultural data collection. The cultures sampled reflect only western industrialized nations, again due to access and cost of international research. Furthermore, the planning measures focus only on perceptions of system characteristics. The measures used were previously validated and most were assessed with multiple items revealing strong reliability. Furthermore, objective as well as subjective measures of performance were used. Additional safe-guards included assessing for response bias and controlling for rival hypotheses or other variables in the firm's context known to affect firm performance.

The implications of this study for practice are somewhat speculative because these results need to be replicated and because of the limitations noted above. Strategic planning processes do seem to matter to firms across various regions and national borders. Strategic planning processes also seem to vary by culture and by performance measure. These conclusions are depicted in Figure 1. Controlling for other contingencies, culture has little direct influence on planning processes and performance; however, it does moderate the planning-performance relationship. Broadly speaking, culture was found to moderate the relationship between planning processes and both subjective and objective measures of performance as indicated by the solid arrows in Figure 1. For example, subjective performance 
appears to be positively affected by the maturity of the planning system in more than one culture. Sales growth is positively affected by both the maturity and the perceived impact of the planning process while ROA is not significantly affected by any of the processes examined in more than one culture. Furthermore, certain planning processes are more likely to lead to improved (subjective) performance depending on the prevailing values in the culture as depicted by the arrow in Figure 1. For example, at higher levels of power distance, planning impact and commitment have a more positive effect on performance. Planning impact and importance have a positive performance effect in cultures having lower levels of uncertainty avoidance; whereas, planning importance has a positive effect on performance where masculine values predominate. Thus, multinationals are wise to consider a multidimensional planning system and multiple performance indicators if they hope to be able to see bottom line benefits from their strategic planning process in a variety of locales.

\section{Figure 1}

Effect of Culture on the Planning-Performance Relationship: A Summary Model

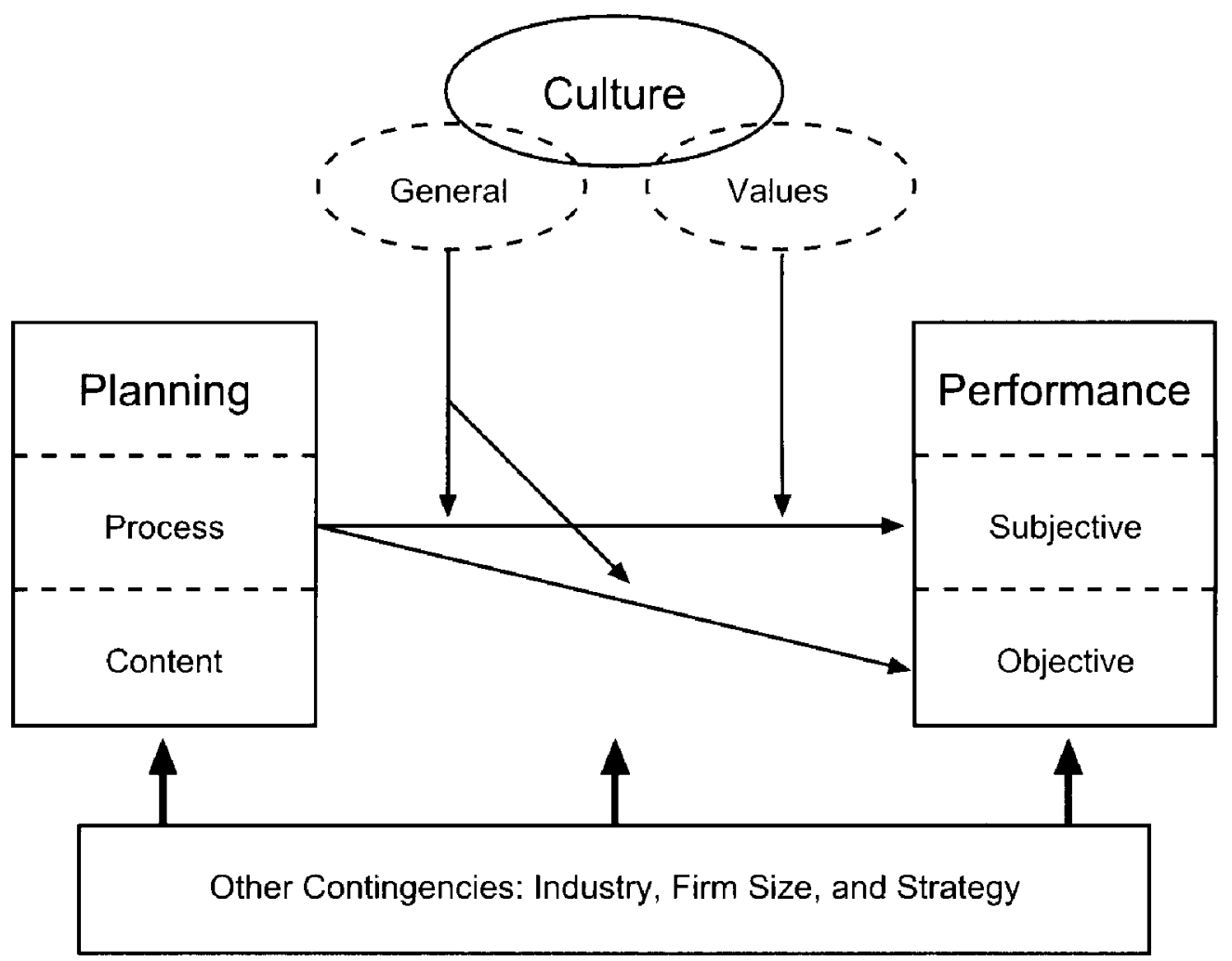

Future research should strive for: larger sample sizes, more divergent cultural groups, and incorporating assessments of strategic planning content as well as 
process in replicating and extending the results found in this study. Research on the preferences for or priorities assigned to certain firm performance measures appears to be warranted. Managers in some cultures may value growth to profitability or short versus long-term performance measures. In addition, the use of specific cultural characteristics should help determine which aspects of culture are particularly germane in explaining the planning-performance relationship. Such research might help further identify the planning and performance characteristics multinationals need to manage in conducting business globally.

\section{References}

Boyd, B. K. (1991). Strategic planning and financial performance: A meta-analytic review. Journal of Management Studies, 28(4), 353-374.

Brews, P. J., \& Hunt, M. R. (1999). Learning to plan and planning to learn: Resolving the planning school/learning school debate. Strategic Management Journal, 20(10), 889-913.

Brock, D. M., \& Barry, D. (2003). What if planning were really strategic? Exploring the strategy-planning relationship in multinationals. International Business Review, 12(5), 543-561.

Brock, D. M., Barry, D., \& Thomas, D. C. (2000). "Your forward is our reverse, your right, our wrong": Rethinking multinational planning processes in light of national culture. International Business Review, 9(6), 687-701.

Burt, D. N. (1978). Planning and performance in Australian retailing. Long Range Planning, 14(2), 62-66.

Capon, N., Farley, J. U., \& Hulbert, J. M. (1994). Strategic planning and financial performance: More evidence. Journal of Management Studies, 31(1), 105-110.

Clark, J. (1990). International marketing and national character: A review and proposal for an integrative theory. Journal of Marketing, 54(Oct.), 66-79.

Dess, G. G., \& Robinson, R. B. (1984). Measuring organizational performance in absence of objective measures. Strategic Management Journal, 5(3), 265-274.

Goll, I., \& Rasheed, A. M. A. (1997). Rational decision-making and firm performance: The moderating role of environment. Strategic Management Journal, 18(7), 583-591.

Grant, R. M. (2003). Strategic planning in a turbulent environment: Evidence from the oil majors. Strategic Management Journal, 24(6), 491-517.

Grinyer, P. H., \& Norburn, D. (1975). Planning for existing markets: Perceptions of executives and financial performance. Journal of the Royal Statistical Society, I38(l), $70-97$. 
Haiss, P. R. (1990). Cultural influences on strategic planning. Heidelberg, Germany: Physica-Verlag.

Harju, P. (1981). Attitude of strategic managers toward formalized corporate planning. Turku, Finland: School of Economics.

Hoffman, R. C., \& Hegarty, W. H. (1993). Top management influence on innovations: The effects of executive characteristics and social culture. Journal of Management, 19(3), 549-574.

Hoffman, R. C., \& Hegarty, W. H. (1983). A model for development of a data collection instrument. Proceedings of the Anntual Meeting of the Academy of Management. Dallas, TX.

Hofstede, G. (2001). Culture's consequences (2nd ed.). Beverly Hills, CA: Sage.

Horovitz, J. (1980) Top management control in Europe. London: MacMillan.

James, W. L., \& Hatten, K. J. (1995). Further evidence on the validity of self-typing paragraph approach: Miles and Snow strategic archetypes in banking. Strategic Management Journal, 16, 161-168.

Javidan, M. (1984). The impact of environmental uncertainty on long-range planning practices of the U.S. savings and loan industry. Strategic Management Journal, $5(4), 381-392$.

Kukatis, S. (1989). The relationship among firm characteristics and design of strategic planning systems in large organizations. Journal of Management, 15(4), 565-579.

Lenartowicz, T. \& Roth, K. (1999). A framework for culture assessment. Journal of International Business Studies, 30(4). 781-798.

Leung, K., Bhagat, R. S., Buchan, N. R., Erez, M. \& Gibson, C. B. (2005). Culture and international business: Recent advances and their implications for future research. Journal of International Business Studies, 36(4), 357-378.

Miles, R. E., \& Snow, C. C. (1978). Organizational strategy, structure and process. New York: McGraw Hill.

Miller, C. C., \& Cardinal, L. B. (1994). Strategic planning and firm performance: A synthesis of more than two decades of research. Academy of Management Journal, $37(6), 1649-1665$.

Ramanujam, V., \& Venkatraman, N. (1987). Planning system characteristics and planning effectiveness. Strategic Management Journal, 8, 453-468. 
Rauch, A., Frese, M., \& Sonnetag, S. (2000). Cultural differences in planning/success relationships: A comparison of small enterprises in Ireland, West Germany, and East Germany. Journal of Small Business Management, 38(4), 28-41.

Rhenman, L. (1973). Organization theory for long range planning. New York: Wiley.

Rhyne, L. C. (1986). The relationship of strategic planning to financial performance. Strategic Management Journal, 7, 423-436.

Rogers, P. R., Miller, A., \& Judge, W. Q. (1999). Using information processing theory to understand planning/performance relationships in the context of strategy. Strategic Management Journal, 20(6). 567-577.

Ronen, S., \& Shenkar, O. (1985). Clustering of countries on attitudinal dimensions: A review and synthesis. Academy of Management Review, 10(3), 435-454.

Rugman, A. (2003). The regional solution: Triad strategies for multinationals. Business Horizons, 46(6), 3-5.

Schneider, S. C. (1989). Strategy formulation: The impact of national culture. Organization Studies, $10(2), 149-168$.

Schneider, S. C., \& Barsoux, J. L. (2003), Managing across cultures (2nd ed.). New York: Prentice Hall.

Schneider, S. C., \& De Meyer, A. (1991). Interpreting and responding to strategic issues: The impact of national culture. Strategic Management Journal, I2(4), 307-320.

Shrader, B., Taylor, L., \& Dalton, D. R. (1984). Strategic planning and organizational performance: A critical appraisal. Journal of Management, 10(2), 149-171.

Sheehan, G. (1975). Long-range strategic planning and its relation to firm size, firm growth, and firm growth variability: An explorative, empirical investigation. Unpublished doctoral dissertation, University of Western Ontario, Canada.

Shortell, S. M. \& Zajac, E. J. (1990). Perceptual and archival measures of Miles and Snow's strategic types: A comprehensive assessment of reliability and validity. Academy of Management Journal. 33(4), 817-832.

Sivakumar, K., \& Nakata, C. (2001). The stampede toward Hofstede's framework: Avoiding the sample design pit in cross-cultural research. Journal of International Business Studies, 32(3), 555-574.

Smith, G. (1980). Planning for productivity. Long-Range Planning, 13, 52-63.

Steensma, H. R., Marino, L. \& Weaver, R. M. (2000). Attitudes toward cooperative strategies: A cross-cultural analysis of entrepreneurs. Journal of International Business Studies, 31(4), 591-609. 
Veliyath, R., \& Shortell, S. M. (1993). Strategic orientation, strategic planning system characteristics and performance. Journal of Management Studies, 30(3), 359-381.

Zahra, S. A., \& Pearce, J. A. (1990). Research evidence on the Miles-Snow typology. Journal of Management, 16(4), 751-768.

\section{Appendix}

\section{Cultural Groups and Their Value Dimensions \\ (means)}

\begin{tabular}{|c|c|c|c|}
\hline Values $^{1}$ & Anglo & Germanic & Nordic \\
\hline Power Distance & $\begin{array}{l}38.8^{\mathrm{h}} \\
\text { (Low) }\end{array}$ & $\begin{array}{l}34.5^{a} \\
\text { (Low) }\end{array}$ & $\begin{array}{l}33.4^{4} \\
\text { (Low) }\end{array}$ \\
\hline $\begin{array}{l}\text { Uncertainty } \\
\text { Avoidance }\end{array}$ & $\begin{array}{l}43.4^{\mathrm{a}} \\
\text { (Low) }\end{array}$ & $\begin{array}{c}61.7^{b} \\
\text { (Med.-Hi) }\end{array}$ & $\begin{array}{c}44.5^{\mathrm{a}} \\
(\text { Low })\end{array}$ \\
\hline Self-Orientation & $\begin{array}{c}90.5^{\mathrm{a}} \\
\text { (Indiv.) }\end{array}$ & $\begin{array}{c}67.5^{\mathrm{b}} \\
\text { (Indiv.-Coll.) }\end{array}$ & $\begin{array}{c}73^{\circ} \\
\text { (Indiv.) }\end{array}$ \\
\hline Assertiveness & $\begin{array}{c}62.9^{a} \\
\text { (Masc.) }\end{array}$ & $\begin{array}{c}67.9^{b} \\
\text { (Masc.) }\end{array}$ & $\begin{array}{c}12.5^{\circ} \\
\text { (Fem.) }\end{array}$ \\
\hline
\end{tabular}

Source: Hofstede (2001).

Within each row values with the same letters are not significantly different from each other based on least significant difference (LSD) post hoc tests.

Richard C. Hoffman, (Ph.D., Indiana University) is a professor of management in the Perdue School of Business at Salisbury University. His teaching and research focuses on strategic and international management. He has published in such journals as Business Horizons, Decision Sciences, Journal of International Business Studies, Journal of Management, and Long Range Planning. Dr. Hoffman has held visiting positions in Asia and Europe and has served as the Chair of the Academy of International Business-Northeast. 